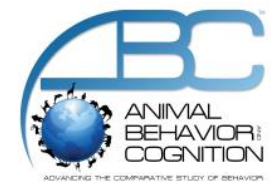

\title{
Different-but-Similar Judgments by Bumblebees
}

\author{
Vicki Xu${ }^{1}$ and Catherine M. S. Plowright ${ }^{1, *}$ \\ ${ }^{1}$ University of Ottawa, Ottawa, Canada \\ *Corresponding author (Email: cplowrit@uottawa.ca)
}

Citation - Xu, V., \& Plowright, C. M. S. (2016). Different-but-similar judgments by bumblebees. Animal Behavior and Cognition, 3(3), 198-209. doi: 10.12966/abc.07.08.2016

\begin{abstract}
This study examines picture perception in an invertebrate. Two questions regarding possible pictureobject correspondence are addressed for bumblebees (Bombus impatiens): (1) Do bees perceive the difference between an object and its corresponding picture even when they have not been trained to do so? (2) Do they also perceive the similarity? Twenty bees from each of four colonies underwent discrimination training of stimuli placed in a radial maze. Bees were trained to discriminate between two objects (artificial flowers) in one group and between photos of those objects in another. Subsequent testing on unrewarding stimuli revealed, for both groups, a significant discrimination between the object and its photo: discrimination training was not necessary for bees to detect a difference between corresponding objects and pictures. We obtained not only object-to-picture transfer, as in previous research, but also the reverse: picture-to-object transfer. In the absence of the rewarding object, its photo, though never seen before by the bees, was accepted as a substitute. The reverse was also true. Bumblebees treated pictures as "different-but-similar" without having been trained to do so, which is in turn useful in floral categorization.
\end{abstract}

Keywords - Bumblebees, Picture-object correspondence, Similarity judgment, Categorization

Because there is natural variability in the visual appearance of individual flowers within a species, managing distortions of an original rewarding stimulus is a requirement for successful foraging. However, recognition of key floral characteristics is necessary to differentiate a rewarding species from other environmental stimuli. Bees are flower constant (Chittka, Thomson, \& Waser, 1999; Raine \& Chittka, 2005, 2007; Rossi, Santos, Salvarrey, Arbulo, \& Invernizzi, 2015), having natural tendencies to exclusively visit certain flower species and prefer matching stimuli. As a result, foraging strategies must include different-but-similar judgements, or the extracting of shared attributes from a rewarding stimuli group, and distinguishing those features from those of unrewarding stimuli groups. These processes may be important in picture-object recognition mechanisms. Although bees do not encounter photographs in nature, counterpart photos and objects are used here to assess different-but-similar judgments

Pictorial stimuli, or floral patterns, are often used in lieu of real world objects in bee research [e.g., photos of flowers (Plowright et al., 2013), artistic representations of flowers (Chittka \& Walker, 2006), color drawings of flowers (Zhang, Srinivasan, Zhu, \& Wong, 2004)] though little is known about picture processing, especially among invertebrates. As noted by Gould (2002), to simply place cues in the vicinity of food and call them "flower learning cues" can lead to mischaracterizations of flower learning processes. To understand pictures as representations of an object, an association from one to the other must be made (Salsa \& de Mendoza, 2007). Fagot, Martin-Malivel, and Dépy (2000) described certain obstacles, such as confusion and independence, to an individual's picture perception. Confusion indicates the subject's inability to distinguish between an object and its 2D representation. For instance, pigeons (Columba livia) displayed attacking behaviors to a photograph of a conspecific as they would to a live 
model (Looney \& Cohen, 1974). Identical behavioral responses were shown to both pictures and objects. On the other hand, independence, where the subject is unable to find similarities between the object and corresponding picture, is demonstrated by the lack of behavioral responses expected to be elicited from objects to pictures or vice versa. For instance, pigeons that were capable of identifying individual humans were unable to transfer the recognition to photographs of the individuals (Dittrich, Adam, Ünver, \& Güntürkün, 2010). Picture-object correspondence can be defined as a transfer or generalization between 2D and 3D stimuli, where too much correspondence results in confusing objects and photos, while too little means the subject fails to see the relation between the two (Weisman \& Spetch, 2010).

Picture recognition is not always reliable, and even among vertebrates, object-to-picture correspondences may fail (e.g., Dittrich et al., 2010). Behavioral responses towards a 3D stimulus do not indicate successful identification of the stimulus's corresponding photograph. A number of cues, such as depth, color, luminosity, and size, are misrepresented in pictorial stimuli for animal studies due to technical constraints (e.g., Delius, Emmerton, Hörster, Jäger, \& Ostheim, 2000). With the increase in research on bee cognition in recent years, results often rely on behavioral responses to pictorial floral patterns in place of real flowers. For instance, simple 2D designs are used to replicate complex elements, such as symmetry (Plowright, Evans, Leung, \& Collin, 2011; Rodríguez, Gumbert, Hempel de Ibarra, Kunze, \& Giurfa, 2004), petal arrangements (Lehrer, Horridge, Zhang, \& Gadagkar, 1995; Séguin \& Plowright, 2008), and spatial frequency (Horridge, 1997). However, behavioral responses to images do not necessarily indicate subjects equate the stimuli with natural floral cues, and accurate processing of images is often a learned ability (Delius et al., 2000).

While there is little investigation in picture-object correspondences in insects, previous research has found insects to be capable of transferring learning of the same features in different stimuli groups. Honeybees (Apis mellifera) were capable of making different-but-similar judgments with mirror images (Gould, 1988). Bees were first trained to discriminate between two patterns, consisting of the same features in different arrangements, and then tested for behavioral responses towards their mirror images. In one test, bees chose the previously rewarding stimulus over its mirror image, ruling out confusion. At the same time, the bees also preferred the mirror image over a novel stimulus. Despite the perceptual differences between the two, mirror images were accepted as a substitute in the absence of a rewarding stimulus. Gould's method of assessing similarity and difference judgements has been used in subsequent research with similar findings using mirror images (Korneluk \& Plowright, 1995), and left-right transformations (Plowright, 1997; Stach \& Giurfa, 2001), and we adopt the method in the present study.

Honeybees also demonstrated positive learning transfers from a stimulus set to novel stimuli that share common features with original stimuli (Benard, Stach, \& Giurfa, 2006). For instance, grouping of similar colors is possible (Benard \& Giurfa, 2008; Dukas \& Waser, 1994) and stimuli within the same color gradients were treated as similar. Additionally, honeybees could discriminate between non-floral Picasso and Monet painting styles (Wu, Moreno, \& Tengen, 2013) with some ability to transfer learning onto novel stimuli. Discriminations between natural scenes, such as trees in forests (Dyer, Rosa, \& Reser, 2008), and flower shapes (Zhang et al., 2004), have also been found.

Previous research on picture-object processing showed bumblebees (Bombus impatiens) to be capable of learning to differentiate between an object and photo with training (Thompson \& Plowright, 2014). Furthermore, learning from object discrimination was also transferred to the corresponding photographs. After an initial discrimination training with two objects, bees preferred the corresponding image of the previously rewarding object over that of the previously unrewarding object.

This study expands further on the previous research by Thompson and Plowright (2014). We examined whether bees could discriminate between counterpart photos and objects even in the absence of prior discrimination training, or whether they confused them. It is possible that picture-object discriminations are like some other pattern discriminations in being so difficult for bumblebees that they require some prior training (e.g., Perreault \& Plowright, 2009). If the discrimination training between pictures and objects could be dispensed with, one research obstacle in floral categorization would be removed. Such a result would suggest that in nature, some of the floral discriminations necessary for categorization could be made without associative learning. 
To explore the boundary conditions of judgments of similarity between objects and pictures, we tested not only object to pictures transfer but also the reverse. While the previous research found bees capable of transferring learning of features of a 3D object to a 2D photograph or even to a silhouette of the object (Thompson \& Plowright, 2014), there is no evidence that bees can also generalize the other way around, where the information present has increased from a degraded photograph to an object. Because in nature members of a rewarding species may either be simpler or more complex than a prototypical flower, learning transfers are expected to go both ways.

\section{Method}

\section{Subjects}

Four colonies of bumblebees (Bombus impatiens) were used for this study, supplied by Koppert Biological Systems Canada. The bees had no experience outside the colony prior to the experiment. The colonies were fed pollen ad libitum and trained with 1:2 sugar to water solution by volume in a radial arm maze. Individual bees were labelled with colored numbered tags glued to the thorax. A total of 20 bees from each colony were tested.

\section{Materials}

The colonies were contained in a plastic cubic box, with a 40-cm tube connecting the container to a rectangular wooden walkway, topped with glass plates. A tunnel of wire mesh connected the walkway to an opening in the center of the maze floor. The radial arm maze consisted of 12 corridors $(14 \mathrm{~cm}$ long and $15 \mathrm{~cm}$ high), which opened into a central area $(17 \mathrm{~cm}$ diameter) from an entrance $(6 \mathrm{~cm}$ wide) (Figure 1). Only 8 of the 12 corridors were in use for the experiment, with the remaining 4 entrances blocked by opaque Plexiglass ${ }^{\circledR}$ dividers. The maze had a clear, Plexiglass ${ }^{\circledR}$ cover $(53 \mathrm{~cm}$ diameter). The opaque grey walls of the maze were also of the same material. Feeder troughs were located at the end of the corridors, and filled with sugar solution or left empty.

Artificial flowers or photographs were also attached to the end of the corridors, with one stimulus per corridor, and bees were able to fly to and touch the stimuli. The stimuli were randomly placed before each training session to ensure no location cues were used. The experiment used two types of synthetic fabric flowers (a single yellow flower (X) and a pink cluster of flowers (Y)). The corresponding color photographs of each flower type were also used (Figure 2). Four copies of both photos or both objects were used during training and testing. The same objects and photos were used from the Thompson and Plowright (2014) study. The photographs were taken using a Panasonic DMC-FZ20 camera and printed with a Canon MP560 ink jet printer with a grey background $(8.5 \mathrm{~cm} \times 10.5 \mathrm{~cm})$. High frequency (> $40 \mathrm{kHz}$ ) light ballasts (Sylvania Quicktronic T8 QHE4x32T8/112 with fluorescent bulbs Sylvania model FO32/841/XP/SS/EC03) were positioned directly above the maze.

\section{Procedure}

The bees were trained in groups and foraged freely in the maze for $3-5 \mathrm{hrs}$ every day for three weeks. The bees were labelled with colored number tags on the thorax as they left the maze and monitored individually. A choice was made when a bee extended its proboscis into the feeders. A new choice was recorded once the bee exited the current corridor and entered another or the same corridor to feed. Satiated bees would leave the maze and go back to the colony, and then return to the maze again for another foraging trip. As with the Thompson and Plowright (2014) study, an individual was selected for testing if it had foraged for two consecutive days and made eight consecutive choices on rewarding stimuli in a given day, three of which had to be different corridors. Should a bee extend the proboscis in an unrewarded feeder, it had to make eight more consecutive choices on the rewarding feeders to qualify 
for testing. The observer noted each time a bee lands on a feeder. After each day of training, the walls and floor of the maze were rinsed and left to dry overnight to eliminate sugar residues.

Upon reaching the training criteria, bees were tested individually. The testing stimuli were placed with empty unrewarding feeders. Choices were recorded when the bee touched either the feeders, stimuli (flower or photograph) or the back wall of the corridor. The bee had to have exited the corridor before another choice was recorded. The first ten choices of each bee were recorded.

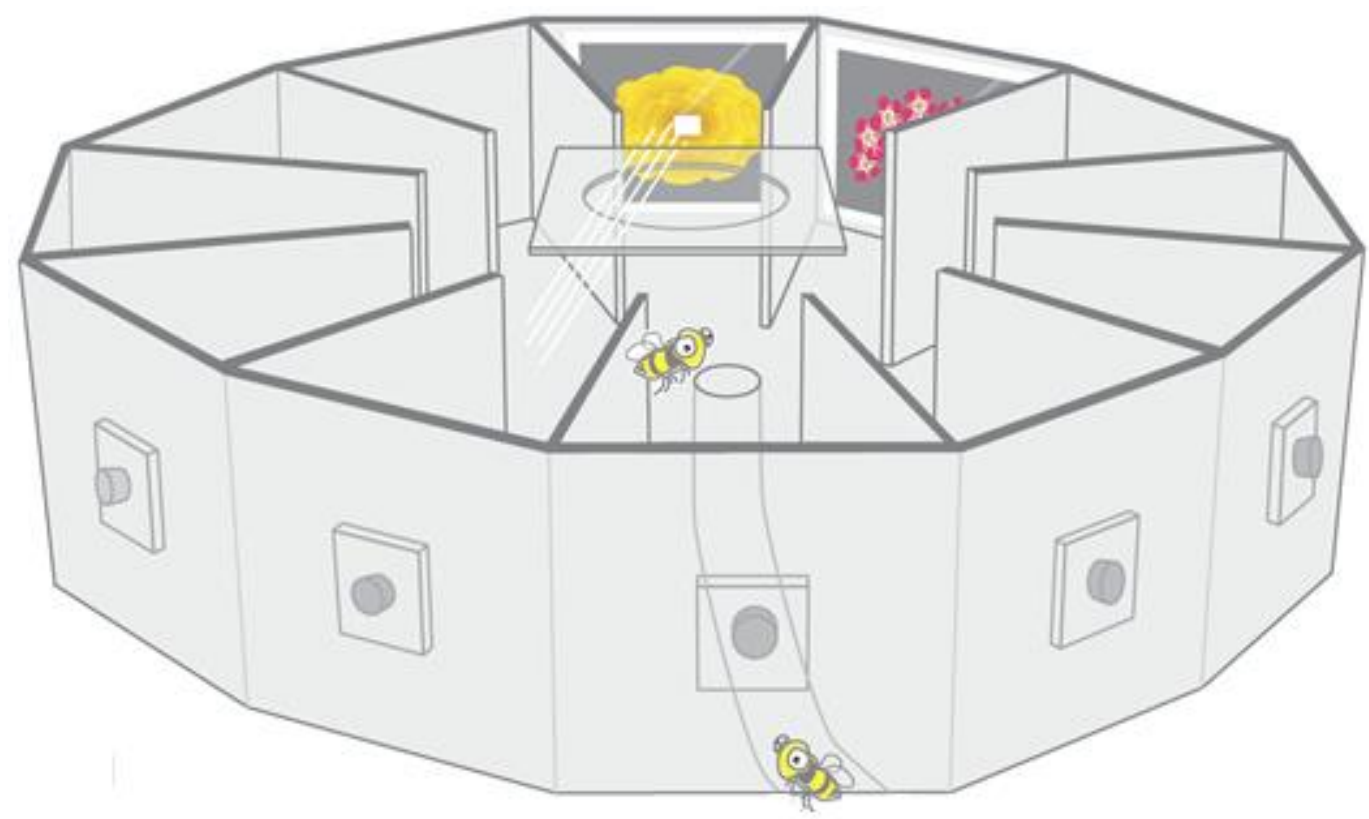

Figure 1. Diagram of bee entering maze through hole in the floor using wire mesh tunnel. Stimuli are mounted on the back walls of the corridors. Figure modified from an original (Plowright et al., 2013) with kind permission from Springer Science and Business Media.

\section{Design}

Two conditions were tested in the experiment, with two colonies trained on the object discrimination (artificial flowers) and two on the photograph discrimination. "Object" and "Photo" are heretofore abbreviated as "Ob." and "Ph.", respectively. In the first condition, the single yellow flower was the rewarding $(+)$ stimulus $(\mathrm{Ob} . \mathrm{X}+)$, while the cluster of pink flowers was the unrewarding $(-)$ stimulus (Ob. Y-) (Table 1). Four copies of each stimulus were placed in the maze. The first colony of bees was trained in that scenario and twenty bees were selected for testing, in two groups of ten. Bees were randomly selected for each of the two groups. The first group was tested using the flower that was rewarding during training, and its corresponding photograph (Ob. $\mathrm{X}$ vs. $\mathrm{Ph}$. $\mathrm{X}$ ). The second group was tested against photographs of the corresponding flowers $(\mathrm{Ph} . \mathrm{X}$ vs. $\mathrm{Ph} . \mathrm{Y})$ to examine if bees accepted the photo in the absence of the previously rewarding stimulus, and learning was transferred from the object to the photo. The stimuli were then counterbalanced (Ob. $\mathrm{X}-, \mathrm{Ob} . \mathrm{Y}+)$ for a second colony (Table 1). Again, twenty bees were tested: half with the previously rewarded flower and its corresponding photograph (Ob. $\mathrm{Y}$ vs. Ph. Y), and the other half with both sets of photographs (Ph. X vs. Ph. Y).

In the second condition, the photograph of $\mathrm{X}$ was rewarding $(\mathrm{Ph} . \mathrm{X}+)$ while the photograph $\mathrm{Y}$ was unrewarding $(\mathrm{Ph}$. Y-) (Table 1). Bees were tested either with the previously rewarded photo and its corresponding object ( $\mathrm{Ph} . \mathrm{X}$ vs. Ob. X), or with the two objects (Ob. X. vs. Ob. Y). The procedure was later counterbalanced for a fourth colony ( $\mathrm{Ph} . \mathrm{X}-, \mathrm{Ph} . \mathrm{Y}+)$ (Table 1) with the bees tested on the photograph and object ( $\mathrm{Ph}$. Y vs. Ob. Y) or objects corresponding to the photographs (Ob. Y vs. Ob. X). Ten bees were used for each set of tests, and the first ten choices of each bee were recorded. 

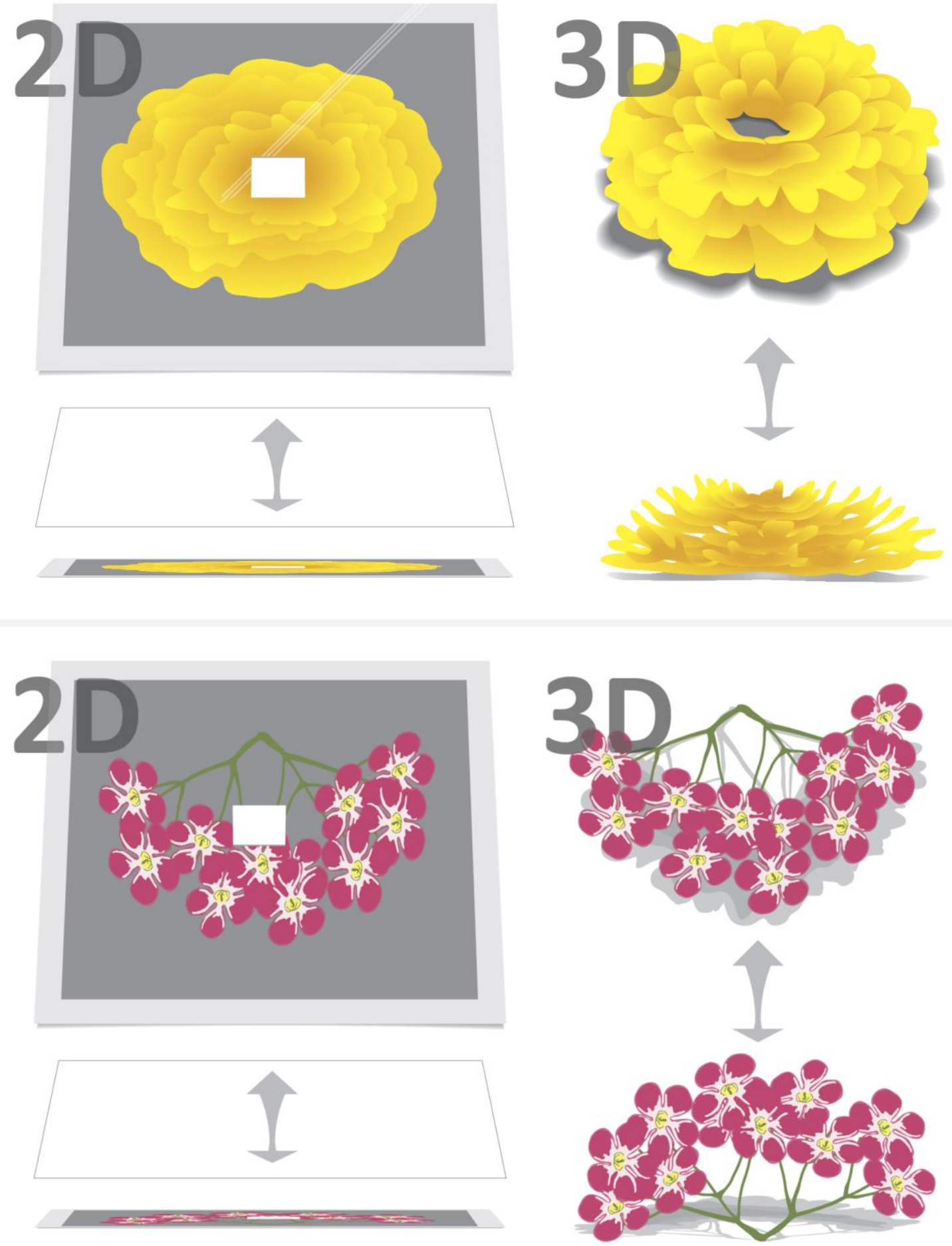

Figure 2. Images of Photo and Object X (on top) and Photo and Object Y (bottom). Object X reproduced from Thompson \& Plowright (2014) with permission from Springer. 
Table 1

Design for Discrimination Training and Subsequent Testing

\begin{tabular}{|c|c|c|c|c|}
\hline & \multicolumn{2}{|c|}{ Colony 1} & \multicolumn{2}{|c|}{ Colony 2} \\
\hline $\begin{array}{c}\text { Train } \\
\text { (20 bees) }\end{array}$ & Object $X_{+}$ & Object Y- & Object Y+ & Object $\mathrm{X}-$ \\
\hline $\begin{array}{c}\text { Test } \\
\text { (10 bees) }\end{array}$ & Photo X & Object X & Photo Y & Object Y \\
\hline (10 bees) & Photo X & Photo Y & Photo Y & Photo X \\
\hline \multicolumn{5}{|c|}{ Discrimination Training on Photos } \\
\hline & \multicolumn{2}{|c|}{ Colony 3} & \multicolumn{2}{|c|}{ Colony 4} \\
\hline $\begin{array}{c}\text { Train } \\
\text { (20 bees) }\end{array}$ & Photo X+ & Photo Y- & Photo Y+ & Photo X- \\
\hline $\begin{array}{c}\text { Test } \\
\text { (10 bees) }\end{array}$ & Object X & Photo X & Object Y & Photo Y \\
\hline (10 bees) & Object X & Object Y & Object Y & Object X \\
\hline
\end{tabular}

\section{Statistical Analyses}

Because the data were binomial with replication within subjects (each having 10 choices), a replicated Goodness of Fit test (Sokal \& Rohlf, 2012) was used to compare choice proportions to a theoretical chance value of 0.5 . The $\mathrm{G}_{\mathrm{P}}$ value determined if the group proportions differed from the theoretical chance value (50:50), while the $G_{H}$ value tested for individual differences. $G$ values were compared to the $\chi^{2}$ value to test for significance.

\section{Results}

\section{Discrimination Training Between Two Objects}

Figure 3 outlines the results of both tests when the rewarded stimulus $(\mathrm{S}+)$ was an object. There was no confusion between the object that had been rewarded during training and its corresponding photograph. The choice proportions for the object were significantly greater than chance, both for Object $\mathrm{X}\left(G_{P}=61.35, p<0.001, d f=1\right)$ and Object Y $\left(G_{P}=21.98, p<0.001, d f=1\right)$. The subjects' first choice favored the previously rewarding object, with 10 of 10 on Object $\mathrm{X}$ and 7 of 10 bees on Object Y. No individual differences were detected $\left(G_{H}=10.33, \mathrm{p}=0.32, d f=9 ; G_{H}=5.77, p=0.76, d f=9\right.$, for Object $\mathrm{X}$ and $\mathrm{Y}$ respectively).

Furthermore, bees were capable of transferring learning from the $\mathrm{S}+$ to the corresponding photograph, which was accepted as a substitute in the absence of the $\mathrm{S}+$. In the absence of Object $\mathrm{X}$ that had been rewarded during training, Photo X was chosen over Photo $\mathrm{Y}\left(G_{P}=20.04, p<0.001, d f=1\right)$. Similarly, in the absence of Object $\mathrm{Y}$ that had been rewarded during training, Photo $\mathrm{Y}$ was chosen over Photo $\mathrm{X}\left(G_{P}=11.79, p<0.001, d f=1\right)$. All 10 bees chose Photo $\mathrm{X}$ as their first choice when Object $\mathrm{X}$ had been rewarding, and 9 of 10 bees chose Photo $\mathrm{Y}$ as their first choice when Object $\mathrm{Y}$ had been rewarding. No significant individual differences were found $\left(G_{H}=10.39, p=0.32, d f=9 ; G_{H}=9.57, p=\right.$ $0.39, d f=9$ respectively). 
A)

\section{Training Object $\mathrm{X}+$, Object $\mathrm{Y}-$}

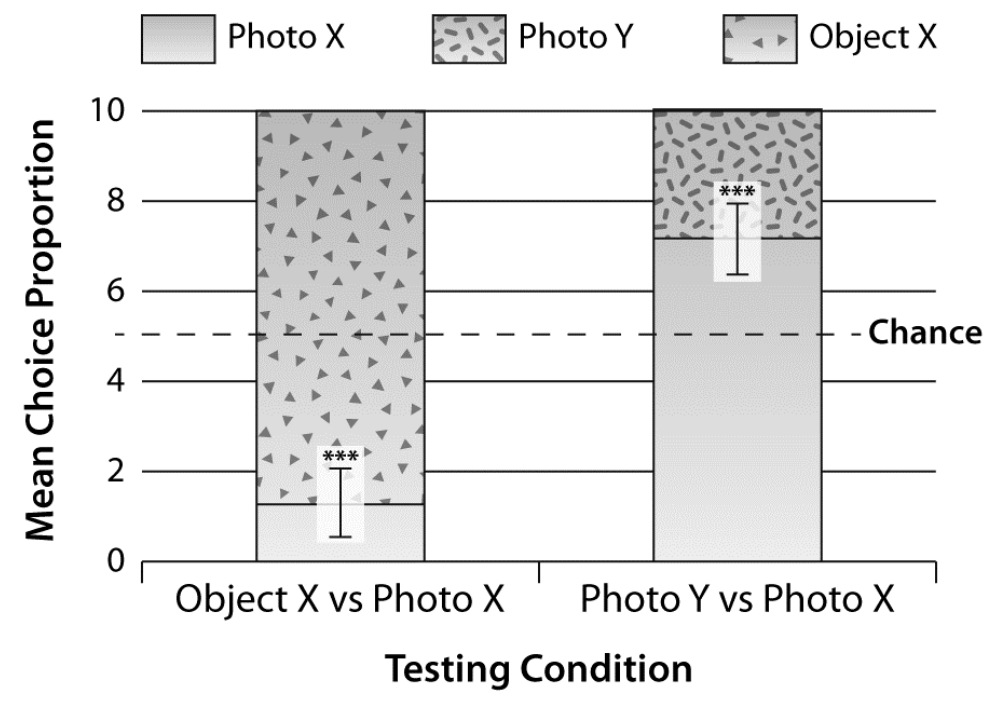

B)

Training Object $Y+$, Object $X-$

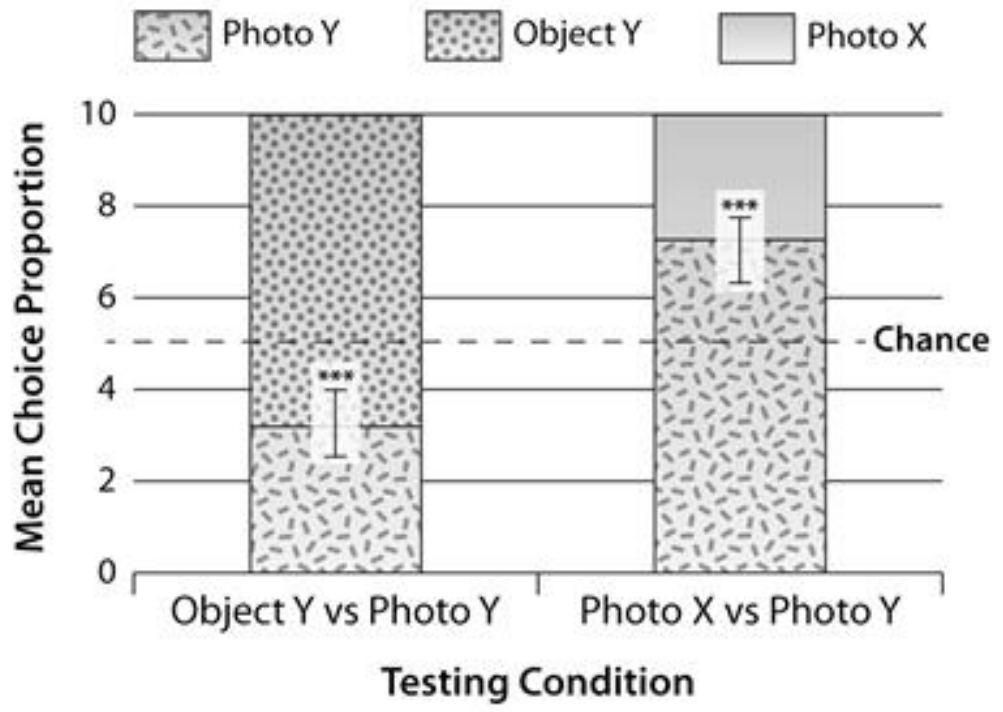

Figure 3. Choice proportions with standard error bars for tests shown in Table 1 for two groups trained to discriminate between two objects. (A) Object X, shown in Figure 2, was rewarding, while Object Y was unrewarding (B) Object Y, shown in Figure 2, was rewarding while Object $\mathrm{X}$ was unrewarding. $* * *$ denotes a choice proportion significantly different from chance, $p<0.001$.

\section{Discrimination Training Between Two Photos}

When the bees were trained with photographs, as shown in Figure 4, there was no confusion between the photo that had been rewarded during training and its corresponding object. The choice proportions for the photograph were significantly greater than chance, both for the $\mathrm{Ph}$. $\mathrm{X}+\mathrm{Ph}$. $\mathrm{Y}-$ group $\left(G_{P}=5.82, p=0.016, d f=1\right)$, with 6 of 10 bees choosing Photo $\mathrm{X}$ as their first choice, and the $\mathrm{Ph}$. $\mathrm{Y}+\mathrm{Ph}$. $\mathrm{X}-$ group $\left(G_{P}=21.98, p<0.001, d f=1\right)$, with 8 of 10 bees choosing the Photo Y as their first choice. No 
significant individual differences were found. $\left(G_{H}=4.18, p=0.90, d f=9 ; G_{H}=6.98, p=0.64, d f=9\right.$ respectively).

A)

\section{Training Photo $\mathrm{X}+$, Photo $\mathrm{Y}$ -}

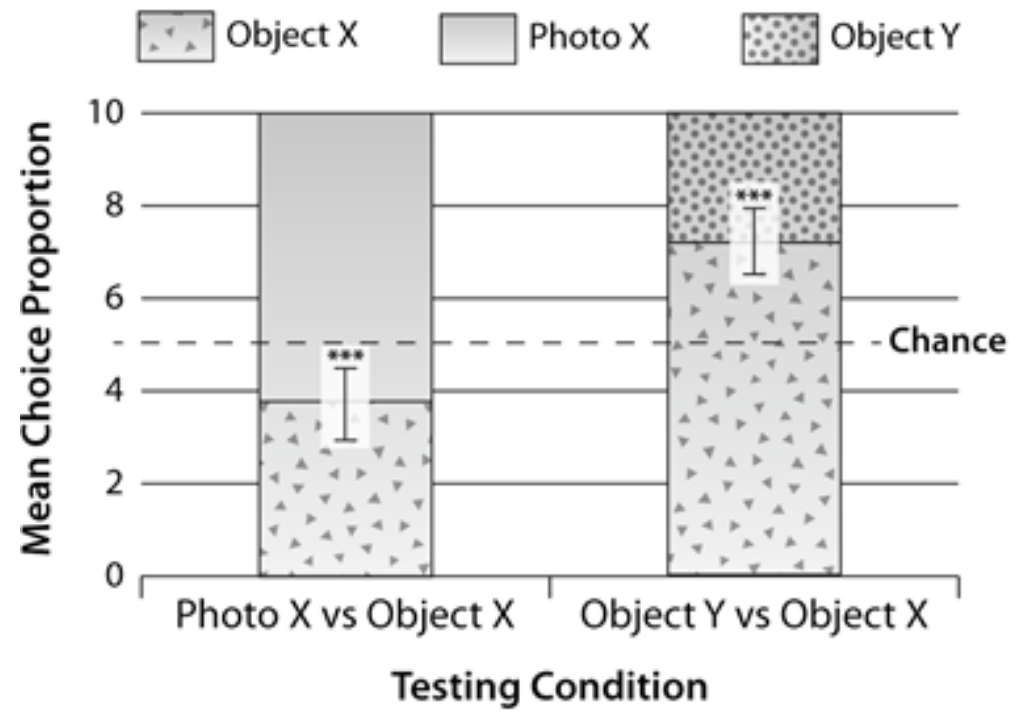

B)

Training Photo $\mathrm{Y}+$, Photo $\mathrm{X}$ -
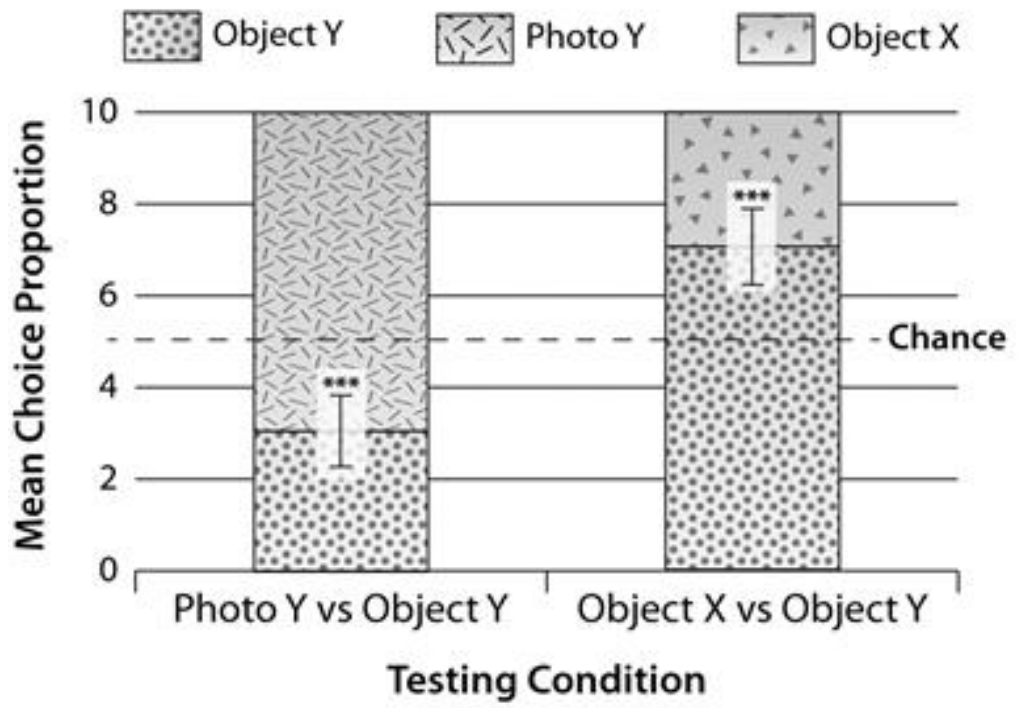

Figure 4. Choice proportions with standard error bars for tests shown in Table 1 for two groups trained to discriminate between two photos of objects. (A) Photo X, shown in Figure 2, was rewarding, while Photo Y was unrewarding (B) Photo Y, shown in Figure 2, was rewarding, while Photo $\mathrm{X}$ was unrewarding. $* * *$ denotes a choice proportion significantly different from chance, $p$ $<0.001$

Furthermore, bees were capable of transferring learning from the S+ to the corresponding object, which was accepted as a substitute in the absence of the $\mathrm{S}+$. In the absence of Photo $\mathrm{X}$ that had been 
rewarded during training, Object X was chosen over Object $\mathrm{Y}\left(G_{P}=21.98, \mathrm{p}<0.001, d f=1\right)$, with 9 of 10 first choices on Object $X$. Similarly, in the absence of Photo $Y$ that had been rewarded during training, Object $\mathrm{Y}$ was chosen over Object $\mathrm{X}\left(\mathrm{G}_{\mathrm{P}}=13.26, \mathrm{p}<0.001, d f=1\right)$, with 7 of 10 bees choosing Object $\mathrm{Y}$ as the first choice. Again no significant individual differences were found $\left(G_{H}=12.69, p=0.18, d f=9\right.$; $G_{H}=11.95, p=0.23, d f=9$ respectively).

\section{Discussion}

In this study on picture-object correspondence in an invertebrate, we developed a way of assessing how bumblebees spontaneously treated a photograph of an artificial flower, having never seen the photograph, and the artificial flower corresponding to the photograph, having never seen the flower. We devised an operational way of testing for their ability to differentiate the two and yet detect a similarity. Following the discrimination training on objects or on photos, half of the bees received one test (for the difference judgement) and half received the other (for the similarity judgement). Given that both subgroups succeeded, and there was no cue as to which of the two tests would be administered, we conclude that all bees could have made either judgement.

The two counterbalanced conditions first tested for unlearned discriminations between a corresponding object and photo. After discrimination training between two objects or photos, bees were tested for preferences between a previously rewarding stimulus and its 2D or 3D counterpart. All bees had a strong preference for the previously rewarding stimuli over the novel counterpart object or photograph, thus demonstrating a capability of discriminating objects and photographs without training or prior exposure to both stimuli. As a result, discrimination training is not necessary for the bees to perceive the difference between photos and objects. This aspect of discrimination will be useful in future studies of categorization. Because many differences exist between objects and photos, being able to discriminate between the two is not surprising. However, as the perceptual system of bumblebees differs greatly from that of humans, testing for difference judgments was necessary to confirm the expectations.

When examining independence (i.e., the inability to see similarities between objects and photographs), the bees were tested with only corresponding photos or objects of the training stimuli and the original $\mathrm{S}+$ and $\mathrm{S}$ - were absent. The bees transferred learning from the rewarding object to its corresponding photo as with previous research (Thompson \& Plowright, 2014) and also from the photo to its object. In the absence of the rewarding object, the corresponding photo was taken as a replacement. The same holds true for rewarding photos, where the corresponding object was preferred as a substitute in the photo's absence. Bees were able to find a similarity both when information is added from a photograph to an object, and when an object is degraded to a photograph.

While the previous study (Thompson \& Plowright, 2014) reported success with a picture-object discrimination on which bumblebees had been trained, here we found no prior discrimination learning was necessary. Moreover, prior experience with photographs was not necessary for the discrimination. Also, there were no significant individual differences found, indicating a possible homogeneous differentbut-similar picture-object perception in bumblebees, likely due to the strict training criteria required for testing. The implications from this study are neither to license the use of $2 \mathrm{D}$ stimuli, nor to argue for its discontinuation. Rather, it is to underscore the caution, made by others (e.g., Spetch \& Friedman, 2006; Weisman \& Spetch, 2010) against untested assumptions regarding how pictures of real objects are treated in animal cognition.

A number of differences exist between objects and their photographs, facilitating discriminations between the two. Elements, such as color, can alter from an object to a photo, and picture capture devices are often designed for human vision only. Photos were also printed on a grey background. Additionally, cues from tactile manipulation of both objects and photos were available, which might be used in discriminating between objects and photos (Chittka, 1998; Chittka \& Thompson, 1997). Despite the differences present between the photographs and the objects, the bees were still able to perceive similarities between the two. This is possible for all counterbalanced conditions, indicating that the qualities of the objects and photographs do not differ too greatly for similar judgements to be impossible. 
While picture object recognition mechanisms may appear to have little ecological relevance to bees in nature, individual flowers within a resource-rich floral species differ from one another, and it would be disadvantageous for a foraging bee to remember details of a single flower rather than common features of the entire species. Here, the photo or object counterparts of the rewarding stimuli might be considered another inflorescence within the same species. Thus, the results do not necessarily entail that bees view images as representations of objects.

In previous research, no transfer in bees was found when images were degraded to drawn pictures (Thompson \& Plowright, 2014), possibly due to a lack of shared features between the images and objects. The differences between a line drawing and an object may be too large for similar features to be perceived. Even among humans, pictorial stimuli are not necessarily treated as representations of their object counterparts (Deregowski, 2000), and behavioral responses are not uniformly defined within groups. While it is unknown whether or not pictures are recognized as representations of objects to bees, experience with the pictures or objects are important in picture recognition (Aust \& Huber, 2010; Watanabe, 2000). In this case, previous training experience on pictures and objects leads to behavioral transfers to the counterpart stimuli. In addition, our results underscore the importance of current context: how bees treated stimuli at the time of testing depended not only on their reinforcement history but also on the alternative that was presented.

Although it is possible that only the most salient cue, such as shape or color, is attended to in discrimination tasks, bumblebees did generalize learning from at least one artificial flower to a black and white silhouette (Thompson \& Plowright, 2014). Moreover, bees have been found to learn multiple elements simultaneously (Ronacher, 1998), suggesting a possible set of features, such as a particular configuration of cues, to be necessary for picture-object identification and categorization (AvarguèsWeber, Deisig, \& Giurfa, 2011; Avarguès-Weber, Portelli, Benard, Dyer, \& Giurfa, 2010).

Because of the perceptual similarities between an object and its corresponding photograph, discriminations and learning transfers between the two may be a result of categorization processes used to identify floral species in nature. Open-ended categories may be possible, where stimuli are grouped based on similar features (Herrnstein, 1990). Previous research has identified the use of open ended categories in honeybees (e.g., Avarguès-Weber et al., 2010; Zhang et al., 2004). Moreover, categorization of floral color was found in bumblebees (Dukas \& Waser, 1994). Subjects not only discriminated within and between groups of stimuli, but also generalized to novel stimuli. However, further research is needed to confirm the role of open-ended categorization in picture-object recognition.

\section{Acknowledgements}

This research was supported by a grant to C.M.S.P. from the Natural Sciences and Engineering Research Council of Canada. We thank Daniel Dostie and Pierre Bertrand for their assistance with the graphic design. Koppert Canada generously donated colonies for our research.

\section{References}

Aust, U., \& Huber, L. (2010). Representational insight in pigeons: Comparing subjects with and without real-life experience. Animal Cognition, 13, 207-218.

Avarguès-Weber, A., Portelli, G., Benard, J., Dyer, A., \& Giurfa, M. (2010). Configural processing enables discrimination and categorization of face-like stimuli in honeybees. Journal of Experimental Biology, 213, 593-601.

Avarguès-Weber, A., Deisig, N., \& Giurfa, M. (2011). Visual cognition in social insects. Annual Review of Entomology, 56, 423-443.

Benard, J., \& Giurfa, M. (2008). The cognitive implications of asymmetric color generalization in honeybees. Animal Cognition, 11, 283-293.

Benard, J., Stach, S., \& Giurfa, M. (2006). Categorization of visual stimuli in the honeybee Apis mellifera. Animal Cognition, 9, 257-270.

Chittka, L. (1998). Sensorimotor learning in bumblebees: Long-term retention and reversal training. Journal of Experimental Biology, 201, 515-524. 
Chittka, L., \& Thomson, J. D. (1997). Sensori-motor learning and its relevance for task specialization in bumble bees. Behavioral Ecology and Sociobiology, 41, 385-398.

Chittka, L., Thomson, J. D., \& Waser, N. M. (1999). Flower constancy, insect psychology, and plant evolution. Naturwissenschaften, 86, 361-377.

Chittka L., \& Walker J. (2006) Do bees like Van Gogh's Sunflowers? Optics \& Laser Technology, 38, 323-328

Delius, J. D., Emmerton, J., Hörster, W., Jäger, R., \& Ostheim, J. (2000). Picture perception in pigeons. In J. Fagot (Ed.), Picture perception in animals (pp. 1-27). Philadelphia, PA: Psychology Press Ltd.

Deregowski, J. B. (2000). Pictorial perception: Individual and group differences within human species. In J. Fagot (Ed.), Picture perception in animals $(397$ - 430). Philadelphia, PA: Psychology Press Ltd.

Dittrich, L., Adam, R., Ünver, E., \& Güntürkün, O. (2010). Pigeons identify individual humans but show no sign of recognizing them in photographs. Behavioural Processes, 83, 82-89.

Dukas, R., \& Waser, N. M. (1994). Categorization of food types enhances foraging performance of bumblebees. Animal Behaviour, 48, 1001-1006.

Dyer, A. G., Rosa, M. G. P., \& Reser, D. H. (2008). Honeybees can recognise images of complex natural scenes for use as potential landmarks. Journal of Experimental Biology, 211, 1180-1186.

Fagot, J., Martin-Malivel, J., \& Dépy, D. (2000). What is the evidence for an equivalence between objects and pictures in birds and nonhuman primates? In J. Fagot (Ed.), Picture perception in animals (pp. 295 - 320). Philadelphia, PA: Psychology Press Ltd.

Gould, J. L. (1988). A mirror-image 'ambiguity’ in honey bee pattern matching. Animal Behaviour, 36, $487-492$.

Gould, J. L. (2002). Learning instincts. In R. Gallistel. (Ed.), Stevens’ handbook of experimental psychology, 3rd ed. (pp. 239 - 257). New York, NY: J. Wiley.

Herrnstein, R. J. (1990). Levels of stimulus control: A functional approach. Cognition, 37, $133-166$.

Horridge, G. A. (1997). Pattern discrimination by the honeybee: Disruption as a cue. Journal of Comparative Physiology A, 181, 267-277.

Korneluk, Y. G., \& Plowright, C. M. S. (1995). Mirror image pattern matching by bumblebees. Behaviour, 132, 8793.

Lehrer, M., Horridge, G. A., Zhang, S. W., \& Gadagkar, R. (1995). Shape vision in bees: Innate preference for flower-like patterns. Philosophical Transactions of the Royal Society B, 347, 123-137.

Looney, T. A. \& Cohen, P. S. (1974). Pictorial target control of schedule-induced attack in white Carneaux pigeons. Journal of the Experimental Analysis of Behavior, 21, 571-584.

Perreault, M., \& Plowright, C. M. S. (2009). Facilitation of learning of a simultaneous discrimination between rotated patterns by bumblebees. Learning and Motivation, 40, 234-256.

Plowright, C. M. S. (1997). Function and mechanism of mirror-image ambiguity in bumblebees. Animal Behaviour, 53, 1295-1303.

Plowright, C. M. S., Evans, S. A., Leung, J. C., \& Collin, C. A. (2011). The preference of symmetry in flower-naïve and not-so-naïve bumblebees. Learning and Motivation, 42, 75-83.

Plowright, C. M. S., Ferguson, K. A., Jellen, S. L., Xu, V., Service, E. W., \& Dookie, A. L. (2013). Bumblebees occupy: When foragers do and do not use the presence of others to first find food. Insectes Sociaux, 60, 517-524

Raine, N. E., \& Chittka, L. (2005). Comparison of flower constancy and foraging performance in three bumblebee species (Hymenoptera: Apidae: Bombus). Entomologia Generalis, 28, 081-089.

Raine, N. E., \& Chittka, L. (2007). Flower constancy and memory dynamics in bumblebees (Hymenoptera: Apidae: Bombus). Entomologia Generalis, 29, 179-199.

Rodríguez, I., Gumbert, A., Hempel de Ibarra, N., Kunze, J., \& Giurfa, M. (2004). Symmetry is in the eye of the 'beeholder': Innate preference for bilateral symmetry in flower-naïve bumblebees. Naturwissenschaften, 91, 374-377.

Ronacher, B. (1998). How do bees recognize visual patterns? Biological Cybernetics, 79, 477-485.

Rossi, N., Santos, E., Salvarrey, S., Arbulo, N., \& Invernizzi, C. (2015). Determination of flower constancy in Bombus atratus Franklin and Bombus bellicosus Smith (Hymenoptera: Apidae) through palynological analysis of nectar and corbicular pollen loads. Neotropical Entomology, 44, 546-552.

Salsa, A. M., \& de Mendoza, O. P. (2007). Routes to symbolization: Intentionality and correspondence in early understanding of pictures. Journal of Cognition and Development, 8, 79-92.

Séguin, F. R., \& Plowright, C. M. S. (2008). Assessment of pattern preferences by flower-naïve bumblebees. Apidologie, 39, 215-224.

Sokal, R. R., \& Rohlf, F. J. (2012). Biometry (4 ${ }^{\text {th }}$ ed). New York: W. H. Freeman. 
Spetch, M. L., \& Friedman, A. (2006). Pigeons see correspondence between objects and their pictures. Psychological Science, 17, 966-972.

Stach, S., \& Giurfa, M. (2001). How honeybees generalize visual patterns to their mirror image and left-right transformation. Animal Behaviour, 62, 981-991.

Thompson, E. L., \& Plowright, C. M. S. (2014). How images may or may not represent flowers: Picture-object correspondence in bumblebees (Bombus impatiens)? Animal Cognition, 17, 1031-1043.

Watanabe, S. (2000). How do pigeons see pictures? Recognition of the real world from its 2-D representation. In J. Fagot (Ed.), Picture perception in animals (pp. 71 - 90). Philadelphia, PA: Psychology Press Ltd.

Weisman, R. G., \& Spetch, M. L. (2010). Determining when birds perceive correspondence between pictures and objects: A critique. Comparative Cognition \& Behaviour Reviews, 5, 117-131.

Wu, W., Moreno, A. M., \& Tangen, J. M. (2013). Honeybees can discriminate between Monet and Picasso paintings. Journal of Comparative Physiology A, 199, 45-55.

Zhang, S., Srinivasan, M. V., Zhu, H., \& Wong, J. (2004). Grouping of visual objects by honeybees. Journal of Experimental Biology, 207, 3289-3298. 